\title{
Correction: Cross-phenotype analysis of Immunochip data identifies KDM4C as a relevant locus for the development of systemic vasculitis
}

Ortiz-Fernández L, Carmona FR, López-Mejías R, et al. Cross-phenotype analysis of Immunochip data identifies KDM4C as a relevant locus for the development of systemic vasculitis. Ann of Rheum Dis 2018;77:589-95.doi:10.1136/annrheumdis-2017-212372.

The additional author, Peter A Merkel, has been added to the author list. The correct order of authors is:

Lourdes Ortiz-Fernández, Francisco David Carmona, Raquel López-Mejías, Maria Francisca González-Escribano, Paul A Lyons, Ann W Morgan, Amr H Sawalha, Peter A Merkel, Kenneth G C Smith, Miguel A González-Gay, Javier Martín, Spanish GCA Study Group, UK GCA Consortium, Turkish Takayasu Study Group, Vasculitis Clinical Research Consortium, IgAV Study Group, AAV Study group.

This has been corrected online.

(C) Article author(s) (or their employer(s) unless otherwise stated in the text of the article) 2018. All rights reserved. No commercial use is permitted unless otherwise expressly granted.

Ann Rheum Dis 2018;77:950. doi:10.1136/annrheumdis-2017-212372corr1 